\title{
PROCESSOS DE CONSTRUÇÃO DO ESPAÇO E DO CORPO BRINCANTE: RECEPÇÃO, CONTAMINAÇÃO E APRENDIZAGEM NA FESTA DO COCO
}

\author{
Petícia Carvalho de Moraes ${ }^{1}$
}

\section{Introdução}

Entre os anos de 2013 e 2016, mergulhei no desafio de estudar algo completamente novo para mim: a Festa do Coco e a brincadeira do coco de roda. Uso o termo novo pois meu corpo ainda desconhecia os fluxos dessa brincadeira e as relações estabelecidas na referida festa.

Desde 2008, eu, formada em Artes Cênicas e atuando nos processos de criação em dança como bailarina e educadora, passei interessar-me por processos que partiam do jogo e da improvisação. Porém, até começar o estudo que resultou em minha dissertação de mestrado ${ }^{2}$ (stricto sensu), não tinha nenhum contato aprofundado com danças e outras práticas comumente denominadas populares (coco de roda, frevo, bumba meu boi, catira etc.). No início de 2014, ingressei formalmente no Programa de Pós-Graduação em Estudos Culturais e pus-me a pesquisar a Festa do Coco e a brincadeira de coco de roda realizadas por duas comunidades quilombolas paraibanas: Ipiranga e Gurugi.

A Festa do Coco é uma festa de ocorrência mensal, que acontece todo último sábado de cada mês na comunidade quilombola Ipiranga, juntamente com a comunidade Gurugi, ambas localizadas no município paraibano de Conde. Essa festa tem na brincadeira do coco de roda seu acontecimento principal. Os participantes da festa, oriundos das duas comunidades, de bairros e cidades próximas e muitas vezes até de outros estados ou países, brincam a noite toda, dispostos em roda, dentro de um barracão. A brincadeira é composta de duas camadas: a primeira refere-se à execução de um movimento comum coletivo em roda e a segunda um jogo de improvisação realizado por uma dupla dentro da roda. Para além da brincadeira, a festa conta com músicos, que tocam e cantam; barracas de comidas e bebidas; um museu, que pretende apresentar para os visitantes como viviam os moradores do quilombo há algumas décadas; e grupos convidados, que vão para a festa apresentar suas práticas e saberes populares antes ou depois da brincadeira de coco de roda.

A Festa é liderada pelo Grupo de Coco de Roda Novo Quilombo, que é formado por moradores dos dois quilombos suprarreferidos e tem como objetivo disseminar a prática do coco de roda por meio de "apresentações" realizadas em diferentes locais do estado da Paraíba e do Brasil. Apesar do uso do termo apresentação, a prática deste grupo não é espetacularizada (ensaiada e coreografada, tendo o público como espectador), pelo contrário, ele busca instaurar a brincadeira em qualquer lugar onde se apresenta.

Durante o processo de estudo, tive como objetivo observar as transformações ocorridas na Festa do Coco e na brincadeira de coco de roda, buscando entender as relações estabelecidas durante o jogo, a participação dos visitantes e a produção de conhecimentos local. A pesquisa empírica foi realizada e registrada em diários de campo de cada festa que participei. Esses diários foram produzidos entre 2013 e 2015, sempre após retornar para São Paulo, resultando em oito descrições de minhas experiências em festa.

\footnotetext{
${ }^{1}$ Escola Técnica de Artes - ETEC: Avenida Cruzeiro do Sul, 2630 - Prédio II - Santana, São Paulo/SP, CEP: 02030-100.E-mail: peticiac@gmail.com.

${ }^{2}$ MORAES, Petícia Carvalho de. A Festa do Coco das comunidades quilombolas paraibanas Ipiranga e Gurugi: acontecimentos e corponegociações. 2016. 161 f. Dissertação (Mestrado em Estudos Culturais) - Escola de Artes, Ciências e Humanidades da Universidade de São Paulo (EACH-USP), São Paulo.
} 
Mesmo não se tratando de uma pesquisa stricto sensu na área da educação, as experiências vividas durante o mestrado e o conhecimento tributário dele, acabaram por transtornar em mim ideias pré-concebidas sobre reprodução, construção e produção de conhecimento - oriundas de meus processos de experiência como educadora, atuando oito anos com formação de profissionais técnicos em dança e teatro na Escola Técnica de Artes (ETEC) do Centro Paula Souza em São Paulo; e com processos criativos emancipatórios no Programa Vocacional da Prefeitura de São Paulo. Portanto, proponho-me neste artigo, a compartilhar acontecimentos vividos durante as festas e estudos realizados, a fim de evidenciar o processo que me levou a entender o aprendizado como um exercício político, e a produzir em mim uma nova ética e uma nova estética do ensinar e do aprender.

Dividi este texto em três partes. Na primeira apresento a metodologia praticada pela brincadeira do coco de roda e confronto minhas escolhas como arte-educadora, focadas na construção de conhecimento conceitual abstrato, com a produção de conhecimento experienciada em jogo, decorrente de processos de contaminação durante a festa. A ideia de contaminação, de ser contaminado pelo outro, por seus movimentos, fez-me repensar o sentido de reprodução e repetição no ensino de dança. Isso leva-me a entender que procedimentos considerados mais convencionais no campo educacional, como o ensino por meio da reprodução, podem ser utilizados quando estes potencializam aprendizados significativos, ou seja, aprendizados que superam a própria reprodução. Essa potência depende da realização de escolhas do educador sobre como conduzir o processo. Já na parte dois, exponho como a Festa do Coco transtornou minha concepção de aprendizado, fazendome saltar da ideia de construção do conhecimento para a ideia de composição do conhecimento. Desta forma, quero crer que, ao problematizarmos os conhecimentos historicamente construídos, estamos a compor, desde a perspectiva da educação como apropriação de conhecimento histórico pelo aprendiz, uma ideia de educação como criação artística, entendendo que uma perspectiva não anula a outra, pelo contrário. Para isso, utilizo-me da Teoria da Recepção de Jauss (JAUSS, 1994) e das experiências vividas em festa para pensar reprodução, construção e produção de conhecimento. Por fim, na última parte, discuto sobre a complexidade existente nos processos de aprendizado, seja na Festa do Coco ou nas relações mais formais de ensino, entendendo o educador como participante desse processo. Sob esse ponto de vista, educador e aprendiz assumem a escolha de estarem em um espaço, por um determinado tempo, construindo e produzindo conhecimento. Nesse sentido, a Festa do Coco e a brincadeira de coco de roda torna-se, então, uma produção de espaçamento por todos: educadores, aprendizes e o próprio conhecimento em jogo.

\section{Transtornando hábitos metodológicos: a produção de conhecimento na festa do coco}

Durante os anos de 2004 e 2007 realizei minha formação de graduação em um curso denominado Educação Artística com habilitação em Artes Cênicas. Neste processo, realizei minhas primeiras incursões na produção de conhecimento de estudiosos das áreas de História da Educação, Psicologia da Educação e de diferentes tendências pedagógicas. Lev Semyonovich Vygotsky, John Dewey, Jorge Larossa Bondia, Paulo Freire, Ana Mae Barbosa, Viola Spolin e Rudolf Laban foram alguns dos quais fizeram parte de minha caminhada inicial. Construí, ao final da graduação, uma concepção de "boa" educação como aquela que possibilitava ao aprendiz o encontro com o conhecimento via domínio de conceitos, do saber pensar e saber fazer de forma autônoma e crítica, e não da reprodução de práticas e discursos.

Nos meus nove anos de atuação como educadora, passando pela Rede Municipal de Ensino de São Paulo e atualmente nos cursos Técnico em Dança, Teatro e como Artista 
Orientadora (citados acima), tive como posicionamento político promover o encontro do aprendiz com conceitos construídos e solidificados na área da dança, do movimento e das artes em geral. Promover esse encontro era, para mim, a possibilidade de poder construir criticamente significados para esses conceitos, isto é, o aprendiz assumia o protagonismo de construir sua própria definição do conceito de "espaço" ou "peso", por exemplo, a partir de experiências provocadas pelo educador durante o encontro; e também pelo seu repertório de vivências anteriores e do contato com definições já criadas por outros estudiosos.

Assim, assumi como procedimento metodológico a construção da ideia de um conceito como ponto inicial ou final de todos os meus encontros, aulas ou processos educativos. Ao lançar a proposta de como poderíamos descrever certo conceito, e, depois de passar algum tempo conversando sobre o entendimento de cada aprendiz e a forma com que alguns pesquisadores o descreviam, mergulhávamos em experiências práticas de aplicação do conceito e de criação por meio dele; ou, iniciava um encontro com uma série de vivências práticas que posteriormente desembocavam em uma conversação sobre determinado conceito, e a construção de sua definição era então levantada pelos aprendizes desde as vivências realizadas naquele encontro, além de suas outras experiências. Percebi que, oferecer ao aprendiz certo "domínio" de um conceito, o permitiria tanto aplicá-lo em algumas situações como desmontá-lo em outras.

Compreender que esse caminho construído por mim buscava se opor a uma das práticas mais comuns no ensino de dança: promover um encontro cujo aprendizado do estudante se dá pela cópia de movimentos, aprendendo tanto a reproduzir os movimentos apresentados, como reconhecendo outras possibilidades de fazer dança. Nesse registro, no entanto, o estudante não consegue pensar como fez/faz tais movimentos ou faria ainda outros. Nessa escolha metodológica, um encontro "bem sucedido" provoca no aprendiz uma ampliação de seu repertório motor, a partir de um modelo externo, o educador. Na maioria das vezes, o aprendiz não consegue construir conhecimento abstrato sobre a área da dança, não articulando, por conseguinte, conhecimento corporal construído de maneira emancipatória (RANCIÈRE, 2004).

Entrei em contato com o conceito de emancipação de Jaques Rancière após meu ingresso, em 2013, como artista orientadora no Programa Vocacional da Prefeitura de São Paulo, existente desde 2001 e mantido por uma série de lutas políticas da classe artística a cada novo ano ou quando ocorre mudanças de gestão. Esse é um dos programas mais revolucionários de formação artística financiados com verba pública na cidade de São Paulo. Isto porque sua proposta metodológica de ensino parte da criação de processos artísticos, mediante um modelo nada tradicional - entendido como aquele no qual o educador é quem domina o conteúdo e determina exatamente o que e como transmitir ao aprendiz -, ou seja, o Artista Orientador do Programa Vocacional auxilia o processo de criação que parte do desejo de todos os presentes: Artista Orientador e Artistas Vocacionados, e que nenhum deles sabe inicialmente como será o processo e nem o produto final. Os artistas envolvidos não têm a responsabilidade de se apegar a nenhum tipo de conhecimento consagrado, mas, sim, de produzir seu próprio conhecimento na linguagem artística que estão trabalhando. Nesse programa, para além da ideia de autonomia (FREIRE, 2011), o artista e o aprendiz desenvolvem potencialidades do fazer e do pensar determinado conhecimento de maneira particular e criativa; o conceito de emancipação (RANCIÈRE, 2004) é usado para fazer com que esta construção autônoma do conhecimento também possibilite a todos, durante o processo, um pensamento sobre a responsabilidade do trabalho coletivo, e de uma produção artística que se relacione com a vida e com a política do viver em sociedade.

Durante os anos que atuei no Programa Vocacional, estive também em processo de mestrado, e pude experienciar outro modo de fazer educação, provocando-me uma série de transtornos. Os processos educativos vividos na Festa do Coco, influenciaram toda a escrita e 
a estética de minha dissertação, bem como minha atuação como artista e educadora. No próximo subitem, compartilho dessa nova experiência.

\title{
1.1. De como os transtornos aconteceram: a metodologia do coco de roda
}

\begin{abstract}
"Para entrar na brincadeira de Coco de Roda o participante deve se juntar a roda e executar um passo básico onde o pé direito se movimenta e o esquerdo serve de base. A roda gira sempre em sentido anti-horário. Fazer parte da roda é um ato de assumir estar na brincadeira, mas ainda em um local de espera desta, pois o jogo acontece dentro da roda. Este local de espera coloca todas as pessoas, de diferentes idades, num movimento único. A intensidade deste movimento varia em relação a idade do participante e o tempo em que se está no jogo. Os olhos voltam-se para o centro, pois todos se fazem participantes e contempladores, artistas e público, ávidos por entrar no centro da roda, mas também interessados em admirar os que estão em jogo. Fora da roda encontram-se: pessoas que querem descansar por um tempo, pessoas que estão esperando a roda esvaziar um pouco - pois o espaço é pequeno para tanta gente - e pessoas que não querem jogar. Fazendo parte da roda deve-se estar preparado para ser tirado por alguém para dançar no meio da roda. Neste meio, duplas brincam juntas de improvisar a partir do passo básico. Não se pode perder o ritmo, mas devem-se criar outras possibilidades de movimentação. Percebi muitos giros, ações de ataque e defesa e ao mesmo tempo muita cumplicidade. Era comum, homens tirarem moças, mas não parecia regra. As jovens moças possuíam uma movimentação sutil, de certa sensualidade. As crianças se desafiavam a manter o ritmo. As características de cada pessoa evidenciavam-se em sua movimentação, porém todos jogavam o mesmo jogo.” (Diário de Campo 1, 27 de julho de 2013)
\end{abstract}

Neste trecho, extraído de meu primeiro diário de campo, descrevo como entendi a brincadeira do coco de roda daquelas comunidades quilombolas. A descrição foi, à época, uma tentativa de organizar meus aprendizados sobre àquela noite e, de forma alguma, abarca a riqueza da brincadeira do coco de roda.

Não existe na festa um momento para o visitante aprender a brincar. A ação, o jogo, são, em si, os próprios aprendizados. A não explicação verbal, antes ou durante a brincadeira, não fixa o que deve ser feito. O primeiro movimento de aprendizado de um participante que se encontra na festa pela primeira vez, se dá ao observar o outro ou os outros. Mas os corpos são diversos, assim como os movimentos, e o que se observa é uma variação constante. As diferentes variações possibilitadas pelo jogo e permitidas pelos brincantes, constroem na festa um mito coletivo sobre o surgimento do jogo: de que o coco de roda tenha surgido da ação e não da sua enunciação, isto é, como se nunca alguém tivesse explicado como se joga, e como se fosse impossível explicá-lo.

A sensação deixada no corpo após a experiência, quer dizer, a memória corporal do vivido, é a de que é impossível descrever o jogo, pois parece ser no "não saber como jogar" que a experiência com o outro se intensifica. Após visitar várias vezes a Festa do Coco, pareceu-me que somente era possível falar sobre ela partindo da minha experiência particular, singular, jamais vivida por outra pessoa durante a festa.

Denominei o processo de aprendizado do coco de roda como processo de contaminação. A contaminação inicia-se quando ponho-me em roda e desejo aprender a execução do passo básico: o participante observa os movimentos dos brincantes e contamina-se das características 
desses movimentos. O corpo mantém-se em roda, desloca-se para a direita, executando um movimento rítmico com os pés. A escuta estabelecida nessa primeira camada do jogo constrói um comum compartilhado (RANCIÈRE, 2009), um consenso: dançar, fazendo parte da roda, e cantar em coro tratam-se de um processo de aprendizado por meio do qual partilha-se um mesmo conjunto sensório-motor.

A contaminação também ocorre pelo jogo que acontece no centro da roda, porém, é um processo de contaminação que gera o dissenso (RANCIÈRE, 2009): observo e escuto o outro para perceber como posso intervir, atravessar, complementar, ou provocar a movimentação do outro. Não mobilizo mais o meu desejo para aprender como reproduzir o movimento do outro, mas como produzir um movimento novo. A contaminação do centro da roda produz partes exclusivas (RANCIÈRE, 2009) para cada participante, ou seja, produz diferença na movimentação, improvisação e criação de novos movimentos.

Assim, os participantes realizam na festa um saber-fazer-dizer o jogo (LABAN, 1978; PESSOA, 2005; SETENTA, 2008), porque o ato de jogar mobiliza o aprendizado, o gesto e a necessidade de comunicar-se com outras pessoas. Durante a festa produz-se conhecimentos (saberes), amplia-se repertórios de movimentos (fazeres) e assume-se o lugar do educador, daquele que fala sobre o jogo para o outro (dizeres). O procedimento da brincadeira de coco de roda transtorna em mim a necessidade de gerar aprendizado via compreensão abstrata de conceitos, pois por meio dele produz-se aprendizado pelo não dito, pelo "não saber como jogar". A brincadeira de coco faz-me entender que há no corpo muito aprendizado que não pode ser dito e endurecido em um conceito. Como perceber esse aprendizado? Como estimulá-lo? Como produzi-lo?

O procedimento da brincadeira de coco de roda também transtorna em mim o sentido da palavra repetição. A repetição do passo básico, na brincadeira, produz um corpo preparado para desenvolver o jogo desde o centro da roda, sensível a sonoridade da brincadeira e conectado com um fluxo coletivo. No coco de roda, o ato de repetir é assumido com intensidade e desejo, porque a repetição não é um ato realizado pela segunda ou terceira vez, e sim um festejar desde a primeira vez (DELEUZE, 2000): o corpo festeja a apropriação do movimento e sua interiorização, ao mesmo tempo que singulariza o movimento e cria uma expressão nova. $\mathrm{O}$ caráter emancipador da brincadeira se dá pelo seu formato em roda, com duas camadas de jogo, e pela sua repetição. O participante sente-se acolhido na roda e pode simplesmente copiar o movimento que vê, movimento este complexo, porém repetitivo. Ao fazer parte da roda, ele aprecia e forja compreensões possíveis para o jogo que acontece no centro da roda. Como não há explicações, também não há certo ou errado, há somente o desejo de se lançar no desafio. Assim, a variação é gerada pela repetição, como se corpo optasse por repetir o movimento pelo seu sinônimo - o corpo está fadado a falar pelos sinônimos, pois nada nele se repete sem alterar aquilo que o produziu anteriormente, e assim o é durante a brincadeira do coco de roda. A poética e a potência do aprendizado estão na intensidade da experiência produzida. A roda de coco alimenta-se da reprodução do movimento, intensificando-se com a produção de novos movimentos (TAVARES, 2013).

Experimentei um novo procedimento de ensino na Festa do Coco, que acontece por repetição e por ter o outro como modelo, mas que detona qualquer possibilidade de se assemelhar a um ensino convencional de dança, pois coloca todos no papel de educador e de aprendiz. A festa possibilita tanto a repetição como a produção da diferença de modo sincrônico, e, assim, produz emancipação pela repetição. Tal procedimento acessa o corpo pela via do sensível, e não do racional, afetando-o pelas relações corporais estabelecidas, pelo acolhimento e pelo desafio. 

de roda?

Mas, afinal, que tipo de aprendizado produz a Festa do Coco e a brincadeira do coco

\section{Transtornando a ideia de aprendizado: as relações entre recepção, experiência e produção de conhecimento}

Durante meu processo de pesquisa de mestrado, minhas concepções sobre aprendizagem e conhecimento também foram desestabilizadas. Costumava, como educadora, entender o aprendizado como um processo de construção de um conhecimento que estava baseado em uma "verdade" declarada pelos pesquisadores, vinculados a diferentes áreas do conhecimento. Assim, mesmo não assumindo o papel de detentora do conhecimento, daquela que deveria fornecer a verdade ao estudante, buscava fazer com que ele trilhasse um caminho de descoberta e invenção daquilo que já existia. O aprendizado consistia em trilhar novamente caminhos já percorridos, como um processo de criação particular de um conceito já estabelecido. Ao trilhar esses caminhos, entendia também que o estudante poderia avançar nas suas descobertas, acessando mais do que o esperado para aquele momento de aprendizado, ou mesmo ampliar o repertório para outros conhecimentos que atravessavam ou se aproximavam do conhecimento esperado.

Entendia que o processo de produção de novidade acontecia como consequência do sólido aprendizado dos conceitos, como se fosse possível somente criar obras artísticas de qualidade após dominar uma série de conhecimentos cristalizados. Muitos educadores da área da dança ainda acreditam que o estudante somente será capaz de criar em dança clássica, por exemplo, depois que fizer oito anos ou mais de aulas de dança e interpretar uma série de balés de repertório. Historicamente, criou-se a ideia, no meio da dança, que criação era algo a ser feito por pessoas que não podiam mais dançar, por motivos de lesão física ou idade avançada, e que, por isso, tornavam-se coreógrafos e criadores na área. Como educadora e artista, percebo a dificuldade em equilibrar importância e responsabilidade de conhecer nossa história, os conhecimentos academicamente solidificados, as conquistas e criações realizadas em certa área etc. e, ao mesmo tempo, entender que o impulso criativo não depende somente desses aprendizados. Compreendê-los pode tanto potencializar atos criativos como impossibilitar que a produção de diferença e a variação aconteçam.

Olhava com mais cuidado para os trabalhos de pesquisa, exploração e criação de meus estudantes quando estes eram avaliativos, e olhava no sentido de verificar, checar, se os conceitos apreendidos encontravam-se ali. Sempre considerei aspectos criativos em minhas avaliações: escolhas estéticas, dramatúrgicas e políticas, mas sempre como um bônus. A criação tornava-se a verificação do sucesso do estudante e do meu sucesso em relação à construção de um conhecimento historicamente consagrado. A Festa do Coco, acontecimento que tem como um de seus objetivos lutar pela manutenção de uma prática já consagrada entre as comunidades quilombolas, parecia provocar esse movimento de valorização dos impulsos criativos dos participantes. Mas, como isso acontecia? Será que este era um movimento consciente por parte dos brincantes e "líderes" da festa?

\subsection{A Festa do Coco e a teoria da recepção: do aprendizado slow food à produção de conhecimento}

Em uma das festas que participei, um dos senhores, integrante do Grupo de Coco de Roda Novo Quilombo, contou-me que há mais de cinquenta anos a divulgação da festa era feita boca a boca. As pessoas avisavam umas às outras que haveria Festa do Coco na casa de fulano. Ainda segundo ele, vinham muitas pessoas de longe para participar da festa, que parou de acontecer 
durante várias décadas nesses quilombos, mas compreendi, por intermédio do relato desse senhor, que o costume de receber pessoas vindas de fora do quilombo e novos visitantes para a festa não era um costume recente e, sim, comum a esta prática. Enquanto participava da Festa do Coco, percebi que seu fluxo assumia o tripé: observar, repetir, criar. Essa lógica dificilmente era verbalizada, mas delineada entre os que já participavam da festa há um tempo:

\begin{abstract}
"Ana deu boa noite a todos no microfone e logo falou que a festa do coco não é uma festa para ser assistida, que a brincadeira do coco de roda é uma brincadeira para todos. Ela afirmou que não há jeito certo ou errado de dançar, que o que importa é entrar na brincadeira e deixar o corpo se mover. A fala de Ana moveu algumas pessoas para compor a roda, que foi crescendo aos poucos até não caber mais gente". (Diário de Campo 8, 31 de outubro de 2015).
\end{abstract}

A lógica estabelecida no jogo, faz com que a cada sábado a festa ganhe características particulares, pois ela realiza-se a partir das memórias corporais e experiências vividas durante o processo de jogo dos participantes, ou seja, a brincadeira acontece com o repertório de movimentos das pessoas que estão no local e com as variações de movimento produzidas do encontro com o outro, que possui outro repertório. Normalmente, as experiências geradas pelos encontros definem a festa para determinado brincante e não suas características gerais ou o "roteiro" do jogo: o brincante vai para casa levando em sua memória corporal aquilo que experimentou.

$\mathrm{Na}$ festa do dia 28 de março de 2015, fui tirada para dançar por um dos idosos da comunidade. Dançar com ele desestabilizou todas as certezas que eu havia criado a partir de minha participação em cinco festas. Ele iniciou uma brincadeira em dupla comigo quando ainda estávamos na formação da roda. Estabelecemos juntos uma relação de aproximação e distanciamento e uma intensidade que quase provocavam umbigadas - termo usado pelos brincantes das práticas populares para definir o movimento por meio do qual os quadris de duas pessoas se encontram através da inclinação da coluna vertebral:

"Essa relação de encontros e desencontros durou muito tempo e adquiriu muita intensidade. Na maior parte das vezes, o desenrolar da brincadeira terminou indo para o centro da roda, onde a aproximação e distanciamento se tornaram maiores, mas permaneceu o encontro do centro dos corpos a todo momento. A relação lado-lado estabelecida pela maioria dos brincantes do centro da roda, modificou-se para frente e trás ou lado e frente. O quadril era levemente projetado para frente nos quase-encontros entre os dois corpos e isso fazia com que todo o corpo fosse envolvido no movimento." (Diário de Campo 6, 28 de março de 2015)

A experiência de dançar com esse senhor foi a de romper todas as regras estabelecidas por mim como apreciadora da festa; regras como: somente manter um passo básico feito na roda, tirar o outro para dançar levando-o para o centro, manter no centro uma relação de lateralidade, não realizar nenhum tipo de toque físico no outro etc. A atração entre nossos corpos fez com que a repetição da movimentação assumisse linhas instáveis e flexíveis, fazendo com que os movimentos ganhassem novas formas e gerassem novos diálogos (ROLNIK, 2011).

Durante as visitas de campo e da compreensão de que não era possível falar da festa de uma forma universalizante ou fixa, mas somente falar do que se viveu, do que se experimentou, tive contato com as pesquisas de Hans Robert Jauss (1994) e sua teoria da Recepção, entendendo-a como as ações de compreensão e envolvimento dos corpos em um acontecimento; 
a teoria da Recepção busca estudar como o corpo recebe uma informação, texto, imagem etc., reagindo a elas.

Uma das ideias que considero importante no pensamento de Jauss é a relação entre o horizonte de expectativa e o que ele classifica como obra artística. Para ele, um fazer adquire consistência artística quando ultrapassa o horizonte de expectativa de seus apreciadores. Ou seja, para que algo seja considerado arte, é necessário que essa prática ultrapasse, tencione e desconstrua as memórias de experiências passadas de seus espectadores e também as ideias prévias sobre como seria aquela experiência. Jauss dialoga com o termo "produção" utilizado por Guattarri e Rolnik (1996) para entender o novo na arte. A produção é um processo de criação humana e maquínica (GATTARRI e ROLNIK, 1996), que não ocorre de maneira espontânea, mas é provocada pela mobilização dos desejos em acontecimento. O termo produzir vem se opor a toda ideia de algo dado a priori, sempre existente. A produção se dá pelo agenciamento (DELEUZE, 1998) desses desejos, ou seja, pelos acoplamentos, trocas e simbioses geradas no encontro com o outro. O novo, considerado por Jauss como verdadeiramente artístico, é aquilo que é produzido durante a experiência artista-espectador, e não o que é afirmado, confirmado ou reproduzido pela obra artística.

Jauss (1994) cria uma metáfora para denominar um fazer que se opõe a produção artística. Àquilo que se afirma pela confirmação da expectativa do espectador seria, então, uma arte culinária. $\mathrm{O}$ autor utiliza esse termo para opor o fazer artístico, àquilo que algumas vezes chamamos de arte utilitária; ademais emprega a metáfora da culinária para agradar todos os públicos. Percebo que seria possível fazer uma "festa culinária", apresentando um coco de roda coreografado, virtuoso e bem executado por todos os integrantes do Grupo de Coco de Roda Novo Quilombo. Poderiam, após esta apresentação, ensinar, verbal e demonstrativamente, como as pessoas podem dançar; deixá-las experimentar em um workshop ou oficina e fazer com que os visitantes saíssem dali com a sensação de como é difícil dançar coco de roda.

Conforme participava das festas do coco, percebia que os participantes saiam encantados pela brincadeira, como se tivessem vivido algo completamente inesperado. Estar na festa era uma escolha, algo provocado pelos corpos presentes, mas o jogo parecia sempre superar expectativas. Importante dizer que uso o termo superar não no sentido de ser melhor, mas no sentido de ser diferente. Se não superava as expectativas durante a maior parte da festa, ao menos provocava novidades em alguns momentos.

Participar de uma festa que possui aspectos artísticos, mas também aspectos sócioantropológicos assemelha-se a um ritual, no qual os mais novos aprendem com os mais experientes, multiplicando-se o conhecimento sobre a brincadeira do coco de roda. Isso fez-me perceber que era possível utilizar as ideias de Jauss para pensar os processos de aprendizagem, substituindo o conceito de arte pelo de conceito conhecimento. O participante vai à festa, assim como um estudante vai à um encontro, com seu horizonte de expectativa. A festa pode então afirmar/confirmar essa expectativa ou produzir um novo conhecimento sobre ela e sobre como acontece a brincadeira do coco de roda.

É interessante perceber o comportamento dos visitantes quando outros grupos exibem suas práticas populares durante a festa: fotografam, olham com admiração e aplaudem. Percebo que é possível brincar com a metáfora da arte culinária e pensar um processo de aprendizagem que poderia acontecer em três camadas na festa: a do fast food, a do slow food e a da arte do conhecimento. Na camada fast food, o conhecimento é reproduzido em forma de informação, o conteúdo é "passado" com sucesso. Na camada slow food o conhecimento é construído, o aprendizado é visto como processo e sua finalidade é levar o aprendiz a elaborar sua concepção sobre um conhecimento já pré-estabelecido. Na camada da arte do conhecimento, este é produzido no encontro, novos conhecimentos surgem em conexão com saberes já estabelecidos. 
Seria possível, então, oferecer o coco de roda de maneira coreografada, espetacularizada em uma apresentação e, depois, explicar como dançar em um formato de vivência, no qual você tenta reproduzir aquilo que te solicitam. Esta seria uma possibilidade de festa fast food. Outra possibilidade seria envolver o participante em uma vivência histórica a partir do emprego de relatos de como era antigamente e, assim, os mais idosos dançariam primeiro, e depois, proporia aos visitantes experimentem a brincadeira. Neste ímpeto saudosista de resgatar a brincadeira, $o$ aprendizado slow food estabelecer-se-ia. Mas, os líderes da Festa do Coco encontraram, não por orientação pedagógica ou filosófica e sim pela lógica da própria brincadeira, um caminho para produzir arte, e, consequentemente, para produzir um aprendizado que se efetiva pela arte do conhecimento. Esse aprendizado não nega nenhum dos anteriores, não nega a importância da informação e nem da construção de um conhecimento já solidificado sobre o coco de roda, mas, amplia, expande e provoca experiências singulares.

É claro que, a reprodução, construção e produção de conhecimento dificilmente ocorrem de maneira isoladas, assim como uma obra artística, para ser considerada artística, não precisa ultrapassar o horizonte de expectativas do espectador em todos os momentos de sua duração e nos aspectos técnicos, conceituais, expressivos etc. É preciso olhar para o todo de um processo educativo, é preciso perceber o que permanece desse processo. As relações estabelecidas durante a brincadeira são complexas e particulares a cada acontecimento.

\title{
3. Da complexidade da brincadeira à complexidade dos encontros educacionais
}

\begin{abstract}
"Durante a brincadeira fui tirada para dançar diversas vezes por uma criança, de aproximadamente onze anos. Diferente das outras pessoas, essa menina ficava a todo tempo no centro da roda escolhendo quem ela chamaria para dançar. Quando ela tirava alguém, ela começava a dançar com essa pessoa e, se ela percebia que não estava dando certo, ela parava a pessoa e explicava como se dançava: - "Vai pro lado, pro centro, pro lado, pro centro, a hora que eu olhar pra você, você gira.". Assim, ela tentava mais algumas vezes e caso não desse certo ela simplesmente parava a brincadeira e levada a pessoa de volta para a roda, puxando pela mão mesmo. Colocava a pessoa na roda e ainda dizia que a pessoa não sabia brincar". (Diário de Campo 6, 28 de março de 2015).
\end{abstract}

A menina, descrita no excerto, provocou em mim uma série de reflexões. Ela provavelmente teve alguma experiência de aprendizado da brincadeira do coco de roda por outros meios que não a própria brincadeira, fazendo com que ela entendesse não somente como deveria dançar, mas que as pessoas que tirasse para dançar no centro da roda deveriam realizar os mesmos movimentos que ela. Essa menina assumiu, então, um papel de detentora do conhecimento naquela festa e sentiu-se interpelada a ensinar outras pessoas durante a experiência da brincadeira. Primeiro, ela eliminou sua relação com a roda ou com o "deixar ser tirada", pois havia compreendido que o jogo, de fato, estabelecia-se no centro, permanecendo nele o tempo todo. Também não tirava as pessoas para dançarem com o pé direito, batendo em frente à pessoa, mas com um apontar do dedo: "escolhi você, venha", era o que dizia em um movimento gestual com os dedos da mão e, às vezes, com a voz também. Ela sempre escolhia pessoas que não eram moradores dos quilombos. Experimentava dançar por alguns segundos e depois parava a pessoa no centro da roda para explicar verbalmente como se dançava. Ela desejava um brincante fast food, alguém que não estivesse ali para aprender, mas para entender. Não tirava pessoas mais experientes da comunidade, pois não estava a fim de improvisar, não estava a fim de criar, de produzir conhecimento. Incorporou um dos papéis possíveis de um educador. 
Depois da explicação rápida de como brincar, ela pedia para ser seguida, experimentava novamente por mais alguns segundos, e caso julgasse que a pessoa não havia entendido, a devolvia na roda, empurrando com seus braços. A menina havia aprendido a brincar o coco de roda mediante sequências de movimento a serem reproduzidas e de explicações verbais. Talvez tivesse experimentado um ensaio com o Grupo de Coco de Roda Novo Quilombo, ou até mesmo uma oficina ministrada pelo grupo. Havia passado por um processo fast ou slow food, porém, como estar em jogo exige agilidade, incorporou a educadora do fast aprendizado. Para sua brincadeira, não era necessário diálogo, improvisação e afetação mútua. Ela desejava afetar, mas não ser afetada. Sob seu ponto de vista, ela brincava de maneira correta e os outros, participantes-visitantes, de maneira errada.

Tirar o outro para dançar é um desafio para todos que brincam de coco de roda, inclusive para as pessoas que compõe o Grupo de Coco de Roda Novo Quilombo. Os participantes da festa, sejam moradores da comunidade ou visitantes, e até mesmo os líderes da festa (membros do Grupo de Coco de Roda Novo Quilombo), atravessam camadas de construção e de produção de conhecimento, assim como assumem momentos nos quais, como educadores, produzem conhecimento no outro ou participam dessa produção. $\mathrm{O}$ mesmo processo de afetação que permite que as regras sejam apreendidas e que o corpo crie a partir delas, também produz certa censura e pode gerar acomodação em decorrência da padronização dos movimentos. "No trato com o movimento, o corpo que dança experimenta a censura a partir da escolha de ações corpóreas que emergem e/ou se repetem no processo de produção da fala" (SETENTA, 2008, p. 34), ou seja, as escolhas realizadas pelo corpo evidenciam como este lida com as informações externas e internas: com os outros, o jogo e com sua memória corporal e repertório de movimentos. As relações são complexas como em toda experiência de encontro. E, como toda experiência de encontro é um processo educativo, as relações estabelecidas em festa foram organizadas como texto para este artigo a fim de provocar e transtornar minhas escolhas como educadora.

Há de se levar em conta as diferentes características de processos educativos formais (escolares e obrigatórios), não formais (oficinas, workshops, seminários etc.) e informais (trabalho, festa, família, entre outros tantos encontros com o outro), porém, não há nada que justifique teoricamente a obrigatoriedade de um aprendizado fast food somente pelo fato de eu estar inserida, como educadora, no contexto do ensino formal. É preciso inverter a chave. Ao invés de olhar para os processos educativos formais a fim de buscar formas de compreender as relações humanas e as experiências de aprendizado que se dão em meios mais informais ou não formais, é preciso olhar com atenção para as experiências informais de encontro com o outro para que elas possam interpelar-me a pensar sobre minhas escolhas como educadora. Inúmeras experiências podem produzir diferença em minhas ações como educadora, e não somente a leitura de livros consagrados na área da educação. A diferença pode ser produzida a qualquer momento, em qualquer mobilização do desejo, em qualquer momento de afetação.

O primeiro transtorno que a festa produziu em mim foi minha mudança de percepção sobre o que eu entendia como aprendizado. O que é aprender? O que deve ser aprendido? Para que aprender? Consequentemente, muitas anomalias surgiram deste transtorno. Essas anomalias eu chamo de outras possibilidades procedimentais, que nada têm de novo no sentido de inovador, mas que podem potencializar outras experiências.

Fazer escolhas políticas tornou-se então um movimento responsável de produzir novas concepções sobre como fazer (metodologias) e para que fazer educação (concepções de aprendizagem e conhecimento). Desejo repensar procedimentos convencionais, como é o caso da repetição de movimentos na dança e entender quando e como eles podem ser potencializadores ou não do conhecimento. Desejo ver-me como uma educadora em produção. 
Desejo fazer parte de uma educação que tenha como ética a produção do transtorno e da anomalia, e, como estética, a produção da diferença.

\section{Considerações finais}

Realizar uma pesquisa acadêmica é também uma possibilidade de vivenciar outros processos de fazer educação. Pesquisar a Festa do Coco, experimentar aquele espaço ritual, artístico e educativo, provocou em mim novos movimentos. Primeiro, entendi os processos educativos como ações efetivas de vida e não ensaios para a vida. Isso fez com que eu, educadora, preocupe-me menos com aquilo que o estudante tornar-se-á e olhe mais para aquilo que está se tornando.

Segundo, os processos de aprendizado formais ou informais, acontecem também pela contaminação. Não há como o educador controlar o que vai ser aprendido e, muito menos, como será aprendido. As escolhas sobre conteúdo, procedimentos de ensino e relação educadorestudante são necessárias para que ele defina a ética e a estética do encontro. Durante um encontro, tudo tem potência de afetar: espaço, corpos, discursos, ações etc. A contaminação se dá de maneira direta: por meio daquilo que foi planejado para o encontro, do "conteúdo" a ser estudado, dos movimentos que devem ser executados ou reproduzidos; e, também, de maneira indireta: expressões faciais, maneiras de agir diante de uma situação, tamanho do espaço escolhido para o encontro etc.

Terceiro, todo ato educativo possui um comum partilhado (RANCIÈRE, 2009), pois é uma ação "provocada" pelos seres que lá se encontram, é uma ação com um objetivo partilhado, porém, provocando em todos, diferentes contágios, fazendo com que o aprendizado e a experiência sejam singulares. Então, como educadora, realizo um movimento de compreender esse aprendizado singular? Como avaliar um aprendizado, buscando entender como este aconteceu no outro, não buscando verificar se o outro sabe aquilo que sei?

Quarto, seria possível pensar em uma experiência educativa, em um encontro, a partir da qual possa se estabelecer inicialmente um processo de acolhimento, um comum partilhado (RANCIÈRE, 2009)? Um espaço onde certo conhecimento seja apalpado por todos, que certa ética seja estabelecida para que todos sintam-se confiantes o suficiente para produzirem novos conhecimentos? É possível pensar as duas camadas da brincadeira do coco de roda como escolha metodológica para encontros formais de educação - a camada do simples, do partilhado, do comum, da repetição e a camada do confronto, do embate, do diálogo e da criação?

Quinto, a partir da Teoria da Recepção de Jauss (1994), podemos também pensar sobre os horizontes de expectativa de um estudante e de um educador e o processo de produção do conhecimento. O educador não deve buscar ultrapassar o horizonte de expectativa do aprendiz via criação de um encontro espetacular. Não são os efeitos, o uso de diversos equipamentos e materiais que definem a potência de um encontro. Se o conhecimento é o cerne de um encontro educador-estudante, a ação de ultrapassar o horizonte de expectativas se dá via produção de conhecimento, isto é, novos conhecimentos emergindo nas relações estabelecidas.

Sexto, como educadora que quer afetar os estudantes, quero ser afetada durante um encontro? Desejo ter meus conhecimentos transtornados durante esse encontro, transformando os próximos encontros e meu não-saber como educadora? Essas escolhas podem definir meu entendimento sobre mediação durante o processo de encontro, pois mesmo que o professor entenda que ele não é dono de um conhecimento, que o conhecimento não está nele, ele sabe que deve dominar muito bem esse conhecimento para realizar essa mediação ou deve, ao menos, dominar muito bem certas técnicas de mediação. Entretanto, se, em um encontro, conhecimentos podem ser construídos e produzidos em diversas direções, o aprendiz pode 
mediar a relação educador-conhecimento e o conhecimento pode, muitas vezes, mediar a relação de afetação educador-estudante. Como aquilo que conhecemos juntos medeia nossas relações de afeto e desejo?

Nesse artigo não busquei responder ou apresentar nenhuma forma ou formato "ideal" de encontro ou de um fazer educativo. Olhar para os saberes compartilhados por uma prática popular foi o movimento que escolhi como artista e educadora para afetar minhas práticas. Esse movimento de estudo produziu alguns conhecimentos sobre educação, e eu os compartilhei aqui. Esse artigo é somente mais um encontro, mais um movimento, mais uma possível afetação.

\section{Referências}

DELEUZE, G. Diferença e Repetição. Tradução de Luiz Orlandi e Roberto Machado. Lisboa: Relógio D’Água, 2000.

DELEUZE, G.; PARNET, C. Diálogos. Tradução de Eloísa Araújo Ribeiro. São Paulo: Escuta, 1998.

FREIRE, P. Pedagogia da Autonomia: Saberes necessários à pratica educativa. 43. ed. São Paulo: Paz e Terra, 2011.

GUATTARI, F.; ROLNIK, S. Micropolítica: Cartografias do Desejo. 4. ed. Petrópolis: Vozes, 1996.

JAUSS, H. R. A História da literatura como provocação à teoria literária. Tradução de Sérgio Tellaroli. São Paulo: Ática, 1994.

LABAN, R. O Domínio do Movimento. São Paulo: Summus, 1978.

PESSOA, J. M. Saberes em festa: Gestos de ensinar e aprender na cultura popular. Goiânia: UCG e Kelps, 2005.

RANCIÈRE, J. O Mestre Ignorante: cinco lições sobre a emancipação intelectual. Tradução de Lilian do Valle. 2 ed. Belo Horizonte: Autêntica, 2004.

A Partilha do sensível: estética e política. Tradução de Mônica Costa Netto. São

Paulo: EXO Experimental org.: Editora 34, 2009.

ROLNIK, S. Cartografia Sentimental: transformações contemporâneas do desejo. Porto Alegre: Sulina: Editora da UFRGS, 2011.

SETENTA, J. S. O Fazer-Dizer do Corpo: dança e performatividade. Salvador: EDUFBA, 2008.

TAVARES, G. M. Atlas do Corpo e da Imaginação: teorias, fragmentos e imagens. Alfragide: Caminho, 2013. 